\title{
Thermal dependence of endurance and locomotory energetics in a lizard
}

\author{
HENRY B. JOHN-ALDER AND ALBERT F. BENNETT \\ Department of Developmental and Cell Biology, University of California, Irvine, California 92717
}

\begin{abstract}
John-Alder, Henry B., and Albert F. Bennett. Thermal dependence of endurance and locomotory energetics in a lizard. Am. J. Physiol. 241 (Regulatory Integrative Comp. Physiol. 10): R342-R349, 1981.-The thermal dependencies of endurance and the rates of oxygen consumption $\left(\dot{\mathrm{V}}_{2}\right)$ and carbon dioxide production $\left(\dot{\mathrm{V}}_{\mathrm{CO}}\right)$ were determined for the lizard Dipsosaurus dorsalis walking on a treadmill. The thermal dependencies of endurance and maximal $\dot{\mathrm{Vo}}_{2}\left(\dot{\mathrm{Vo}}_{2}\right.$ max $)$ are nearly identical. The maximal sustainable speed and the speed at which $\mathrm{VO}_{2}$ max is attained at each experimental body temperature are the same. The net cost of locomotion (the slope of $\dot{\mathrm{Vo}}_{2}$ vs. speed) is temperature independent. Resting $\dot{\mathrm{Vo}}_{2}$ and the incremental change in $\dot{\mathrm{V}}_{2}$ required to support locomotion at a sustainable speed are higher at $40^{\circ} \mathrm{C}$ than at $25^{\circ} \mathrm{C}$. Therefore, the total cost of locomotion $\left(\mathrm{VO}_{2} \div\right.$ speed) is greater at $40^{\circ} \mathrm{C}$. However, the minimum cost of transport, attained at the maximal sustainable speed, is temperature independent. The results clearly indicate that maintenance of a high body temperature is energetically expensive for Dipsosaurus, but that the associated expanded activity capacity enables this lizard to avoid an obligate increase in the energetic requirements of locomotion.
\end{abstract}

Dipsosaurus dorsalis; oxygen consumption; treadmill; net cost of locomotion; total cost of locomotion; minimum cost of transport; carbon dioxide production; endurance; exhaustion; activity metabolism; exercise physiology

THE ENERGETIC BASIS OF LOCOMOTION in animals has been an area of active research and discussion for the last decade, attracting the interests of physiologists, morphologists, and ecologists. As speed of locomotion (power output) increases, oxygen consumption (power input) increases according to a pattern characteristic of the mode of locomotion employed. During terrestrial quadrupedal locomotion, the rate of oxygen consumption $\left(\dot{\mathrm{VO}}_{2}\right)$ increases linearly with speed until a maximal $\dot{\mathrm{Vo}}_{2}$ $\left(\dot{\mathrm{VO}}_{2}\right.$ max $)$ is attained. Such a dependence of locomotory energetics has been reported in both mammals (see Ref. 21) and lizards $(1,12,14)$. The speed at which $\dot{V}_{2} \max$ is attained is termed the maximum aerobic speed. Further increases in speed require additional anaerobic metabolic support and result in exhaustion of the animal.

Locomotory energetics are closely related to $\dot{\mathrm{Vo}}_{2}$, and aerobic metabolic processes are generally very temperature dependent. Consequently, a comparable thermal dependence of energetics and endurance is anticipated. This thermal dependence is of particular importance to ectotherms that experience considerable daily and/or seasonal variation in body temperature $\left(T_{b}\right)$ and must withstand the effect of temperature on various physiological processes, including $\mathrm{Vo}_{2}$. The thermal dependence of locomotory energetics per se has received little direct examination. Instead, investigators have used metabolic indices of thermal dependence and drawn inferences concerning activity capacity. Fry (13) interpreted the difference between maximal and resting $\mathrm{V}_{2}$, the aerobic metabolic scope (3), as being the potential of an organism for doing work. Accordingly, this potential is maximal at that temperature or range of temperatures in which aerobic scope is maximal. Direct measurement of the thermal dependence of locomotory energetics is of particular importance in establishing the validity of predicting work potential on the basis of aerobic scope.

Lizards are a particularly suitable group of animals for an investigation of the thermal dependence of locomotory energetics. They are exposed to a broad range of $T_{b}$ in normal circumstances, particularly thermophilic species that are active at relatively high $\mathrm{T}_{\mathrm{b}}$. We have investigated locomotory energetics of one such species walking on a treadmill under controlled thermal conditions. Experiments were done on the desert iguana, Dipsosaurus dorsalis, a common inhabitant of the deserts of southern California. This lizard thermoregulates within narrow limits of its preferred body temperature (PBT), determined to be $38.5^{\circ} \mathrm{C}$ in a laboratory thermal gradient (11) and $42.1^{\circ} \mathrm{C}$ under field active conditions (19). Body temperature in Disposaurus can fall to lower levels at night, particularly during the spring. Therefore, this species may undergo substantial diurnal fluctuations in $T_{b}$. $\mathrm{V}_{\mathrm{O}_{2} \text { max }}$ of Dipsosaurus increases greatly between 25 and $40^{\circ} \mathrm{C}(7)$. Since $\dot{V}_{2}$ increases linearly with speed, and since increases in speed above that at which $\dot{\mathrm{V}}_{\mathrm{O}_{2} \text { max }}$ is attained require additional anaerobic metabolic support and are not sustainable, it is anticipated that capacity to sustain locomotion, i.e., endurance, will show a thermal dependence similar to that of $\dot{V}_{\mathrm{O}_{2} \text { max. The purposes of }}$ this investigation were to define the thermal dependence of endurance and to describe the effects of temperature on $\dot{\mathrm{VO}}_{2}$, the rate of $\mathrm{CO}_{2}$ production $\left(\dot{\mathrm{VO}}_{2}\right)$, and locomotory energetics in Dipsosaurus at 25 and $40^{\circ} \mathrm{C}$.

\section{MATERIALS AND METHODS}

Adult desert iguanas ( $D$. dorsalis) were collected during October 1979 in Riverside County, California (California Scientific Collecting Permit no. 514) and were transported to the University of California, Irvine, where 
experiments were performed. They were housed in glassfronted, wooden terraria equipped with incandescent lamps set on a $12: 12 \mathrm{~h}$ day-night light cycle permitting behavioral thermoregulation. The animals were maintained in good health on a mixed diet of lettuce, canned dog food, mealworms, and fresh blossoms of common butterweed, Senecio vulgaris. Access to water was unrestricted.

Animals were tested for willingness to walk on a motordriven treadmill over a range of sustainable speeds under the conditions described below. Eighteen lizards (mean body weight, $51.3 \mathrm{~g}$; range, $33.0-62.0 \mathrm{~g}$ ) were selected. Experiments were performed between December 1979 and March 1980. No individual was exercised more than once in 2 days. The experiments at $25^{\circ} \mathrm{C}$ were completed before those at $40^{\circ} \mathrm{C}$ were begun.

On the day of an experiment, lizards were transferred into a constant-temperature chamber and allowed at least $1 \mathrm{~h}$ for thermal equilibration. An animal was then weighed, its cloacal body temperature was measured, and it was fitted with a lightweight transparent acetate mask, closed except for the head opening and an excurrent air port. The mask was harnessed loosely around the animal's neck, and the excurrent air line, consisting of Tygon tubing (OD $1 / 8$ in.), was taped to the animal's back and tail. Air was drawn through the mask at a measured rate of 420-435 $\mathrm{ml} \cdot \mathrm{min}^{-1}$ (STPD) with a downstream diaphragm pump. Through this arrangement, air in the fitted mask was refreshed continuously with incurrent ambient air flowing between the mask and the animal's head and neck. The masked animal was placed in a cloth sack and put on the motionless treadmill for a 15- to 20min rest period before experimentation. Surface temperature was regulated with a variable radiant heater and a small blower for convection.

Measurement of preactive oxygen consumption $\left(\dot{\mathrm{VO}}_{2 \text { rest }}\right)$ and carbon dioxide production $\left(\dot{\mathrm{V}} \mathrm{CO}_{2 \text { rest }}\right)$ was made for 8-10 min immediately prior to walking. Then, the animal was removed from the cloth sack and its body temperature was again measured. The treadmill was accelerated to the desired speed, monitored continually with a tachometer, and the animal was placed on the moving surface. The tread belt was made of rubberimpregnated cloth with an effective length of $70 \mathrm{~cm}$ and a width of $15 \mathrm{~cm}$. The treadmill was powered by a DC motor and had a speed range of $0.1-3.2 \mathrm{~km} \cdot \mathrm{h}^{-1}$. The animal was stimulated by tail- and toe-pinching and prodding with a wooden stick. Timing was begun at the onset of walking, which occurred usually within a few seconds of the animal being placed on the treadmill. Walking was continued for 15 min or until further stimulation elicited no further walking, the animal becoming exhausted, unable to maintain the treadmill pace, and falling off the back end of the treadmill. At the end of the run, elapsed time was noted and cloacal body temperature was measured. On rare occasions, an animal could not be coaxed into walking. These trials were discontinued. Another series of experiments was done to establish whether the mask and air line impeded locomotory capacities.

Air pulled through the mask went through a series of apparatus including, sequentially, a $50-\mathrm{ml}$ surge tank, a column of indicating Drierite containing about $25 \mathrm{ml}$ of air space, an Applied Electrochemistry model S-3A oxygen analyzer, a Beckman model LB2 infrared carbon dioxide analyzer, a Brooks rotameter, and a diaphragm pump. Records of the concentrations of $\mathrm{O}_{2}$ and $\mathrm{CO}_{2}$ in the dried excurrent air were made on a Honeywell dualpen flatbed recorder. There was a constant delay of $28 \mathrm{~s}$ between a change in gas concentration at the mask and attainment of $90 \%$ of full response on the recorder. These delays have been taken into account in the subsequent presentation.

The longest period of stable $\mathrm{O}_{2}$ consumption and $\mathrm{CO}_{2}$ production, counting back from the end point, was used for the purpose of analyzing a chart record. The initial minute of the record was never included. Periods of measurement ranged from 1 to 12 min $($ mean $=6)$. The area defined by the base line, the gas record, and the end lines of the measurement segment were integrated via polar planimetry. The fractional concentration of each gas in the excurrent air (FE) was calculated from the appropriate measurement; the fractional concentration of each gas in the inspired air (FI) was taken as its concentration in room air. $\dot{\mathrm{V}} \mathrm{O}_{2}$ and $\dot{\mathrm{V}} \mathrm{CO}_{2}$ were calculated according to the following equations

$$
\begin{aligned}
\dot{\mathrm{V}} \mathrm{O}_{2}= & {\left[\left(\mathrm{FI}_{\mathrm{O}_{2}}-\mathrm{FE}_{\mathrm{O}_{2}}\right)(\dot{\mathrm{VE}})(60)-\left(\dot{\mathrm{V} C \mathrm{O}_{2}} \cdot \mathrm{FI}_{\mathrm{CO}_{2}}\right)\right] } \\
& \div\left[\left(1-\mathrm{FI}_{\mathrm{O}_{2}}\right)(m)\right] \\
\dot{\mathrm{V}} \mathrm{CO}_{2}=\left(\mathrm{FE}_{\mathrm{CO}_{2}}-\mathrm{FI}_{\mathrm{CO}_{2}}\right)(\dot{\mathrm{VE}})(60) & \div m
\end{aligned}
$$

where $\dot{\mathrm{VO}}_{2}$ is mass-specific oxygen consumption $\left(\mathrm{ml} \mathrm{O}_{2}\right.$ $\left.\mathrm{STPD} \cdot \mathrm{g}^{-1} \cdot \mathrm{h}^{-1}\right) ; \mathrm{VCO}_{2}$ is mass-specific carbon dioxide production ( $\mathrm{ml} \mathrm{CO} \mathrm{CO}_{2}$ STPD $\left.\mathrm{g}^{-1} \cdot \mathrm{h}^{-1}\right)$; $\mathrm{F}_{\mathrm{I}}$ is fractional concentration of gas in inspired air; $\mathrm{FE}$ is fractional concentration of gas in excurrent air; $\dot{V E}$ is flow rate $\left(\mathrm{ml} \cdot \mathrm{min}^{-1}\right.$ STPD); $m$ is body mass in grams. Conditions for the valid application of $E q .1$ as presented by Withers (24) were met.

\section{RESULTS}

The capacity to sustain walking as a function of speed is reported as time on the treadmill in Fig. 1. Between 25 and $40^{\circ} \mathrm{C}$, endurance is strongly influenced by temperature: the highest speed at which more than half of the lizards could sustain 15 min of walking increased from $0.3 \mathrm{~km} \cdot \mathrm{h}^{-1}$ to $0.8 \mathrm{~km} \cdot \mathrm{h}^{-1}\left(\mathrm{Q}_{10}=1.93\right)$. As speed was increased above these levels at their respective temperatures, time on the treadmill declined progressively until the animals could sustain only about $2-3$ min of walking before becoming exhausted and falling off the treadmill. At each experimental temperature, this decline in time on the treadmill is described by an equation of the form $\mathrm{T}^{-1}=a \mathrm{~S}+b$ where $\mathrm{T}$ is time on treadmill, $\mathrm{S}$ is speed, and $a$ and $b$ are empirically determined constants.

$$
\begin{aligned}
25^{\circ} \mathrm{C}: \quad \mathrm{T}^{-1} & =0.367(\mathrm{~S})-0.022 \\
n & =37 ; r=0.74 ; P<0.0005 \\
40^{\circ} \mathrm{C}: \quad \mathrm{T}^{-1} & =0.430(\mathrm{~S})-0.283 \\
n & =53 ; r=0.78 ; P<0.0005
\end{aligned}
$$




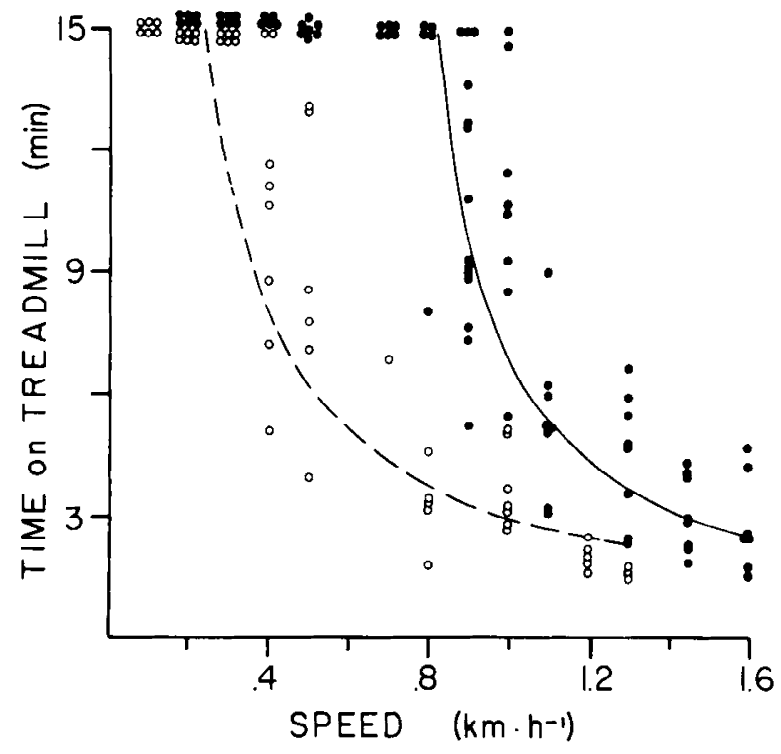

FIG. 1. Capacity of Dipsosaurus to sustain walking. Data are reported as time voluntarily sustained on treadmill at different speeds. Open circles, data collected at $25^{\circ} \mathrm{C}$; closed circles, data collected at $40^{\circ} \mathrm{C}$. Walking trials were terminated at $15 \mathrm{~min}$ or after exhaustion of lizard.

Any limitation on endurance imposed by the mask would be manifested as a left-shift in the plots of Eqs. 3 and 4 (see Fig. 1). To test this possibility, time on the treadmill of masked and unmasked animals was compared (Fig. 2). Speeds chosen for these comparisons were $0.4 \mathrm{~km} \cdot \mathrm{h}^{-1}$ at $25^{\circ} \mathrm{C}$ and $0.9 \mathrm{~km} \cdot \mathrm{h}^{-1}$ at $40^{\circ} \mathrm{C}$, each speed being $0.1 \mathrm{~km}$. $\mathrm{h}^{-1}$ greater than the maximum sustainable speed at that temperature. The difference between mean times on the treadmill of masked and unmasked animals, whether or not the 15-min trials are included, is not significant at either $25^{\circ} \mathrm{C}(P>0.5)$ or $40^{\circ} \mathrm{C}(0.2>P>0.1)$ (see Fig. 2). Thus, there was no measurable limitation on endurance imposed by the mask.

Mass-specific $\mathrm{O}_{2}$ consumption $\left(\mathrm{V}_{2}\right.$ ) of animals on the treadmill is reported in Fig. 3. The difference between the average resting $\dot{\mathrm{V}}_{2}\left(\tilde{V}_{\mathrm{O}_{2}}\right.$ rest reported as mean $\pm \mathrm{SE}$ ) obtained at $25^{\circ} \mathrm{C}\left(\overline{\mathrm{V}}_{2}\right.$ rest $=0.140 \pm 0.045 \mathrm{ml} \mathrm{O} \cdot \mathrm{g}^{-1}$. $\left.\mathrm{h}^{-1} ; n=4\right)$ and that obtained at $40^{\circ} \mathrm{C}$ ( (ั) $_{2}$ rest $=0.319 \pm$ $\left.0.07 \mathrm{ml} \mathrm{O} \cdot \mathrm{g}^{-1} \cdot \mathrm{h}^{-1} ; n=8\right)$ is significant $(t=2.598, P<$ $\left.0.025 ; Q_{10}=1.74\right)$.

At each temperature, $\dot{V}_{O_{2}}$ increases linearly with speed up to a maximal level $\left(\dot{\mathrm{V}}_{2}\right.$ max $)$. This level is maintained at higher speeds. The data for each temperature presented in Fig. 3 are described by the best-fitting pair of linear equations, chosen by a procedure modified from Wilson (23). Initially, the data for each temperature, excluding $\mathrm{VO}_{2}$ rest, were divided according to speed into two subsets, each of which contained $\dot{\mathrm{V}} \mathrm{O}_{2}$ values for at least two speeds. A linear equation for each subset was generated via bivariate regression analysis, and the residual sums of squares for the two equations were added to yield one value per pair of equations. The dividing speed was increased sequentially until all possible pairs of subsets had been subjected to similar analysis. The pairs of equations used to describe the data in Fig. 3 were chosen by the criterion of minimizing the summed residual sums of squares.
The following linear equations best describe the relationships between speed and submaximal $\mathrm{VO}_{2}$

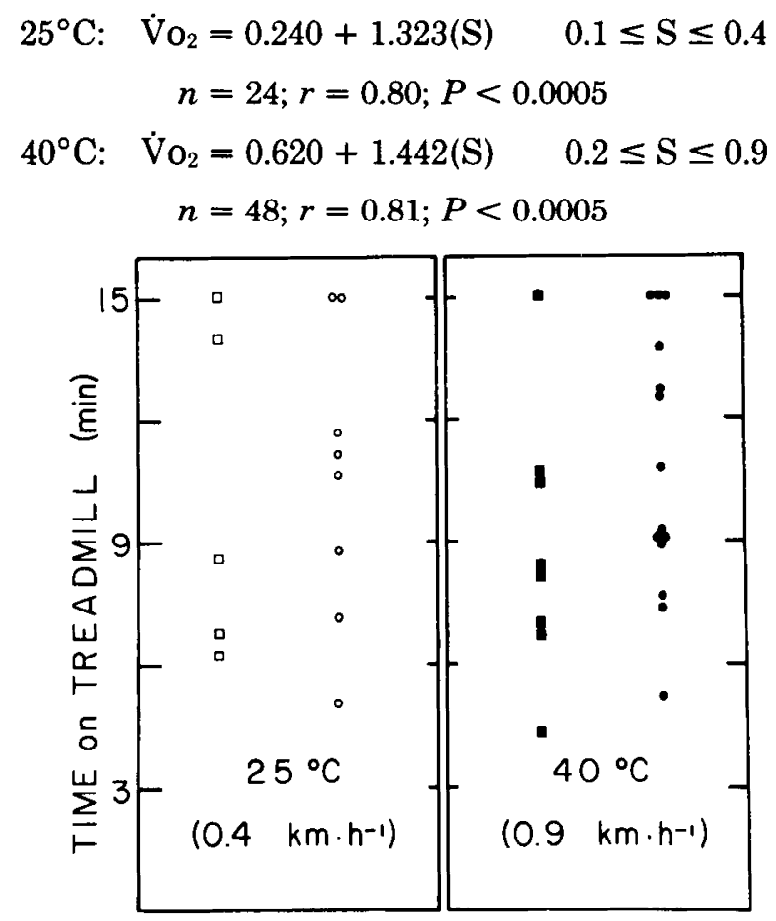

FIG. 2. Time on treadmill of masked and unmasked Dipsosaurus walking at $25^{\circ} \mathrm{C}$ (open symbols) and $40^{\circ} \mathrm{C}$ (closed symbols). Squares, individual values from unmasked animals; circles, masked animals.

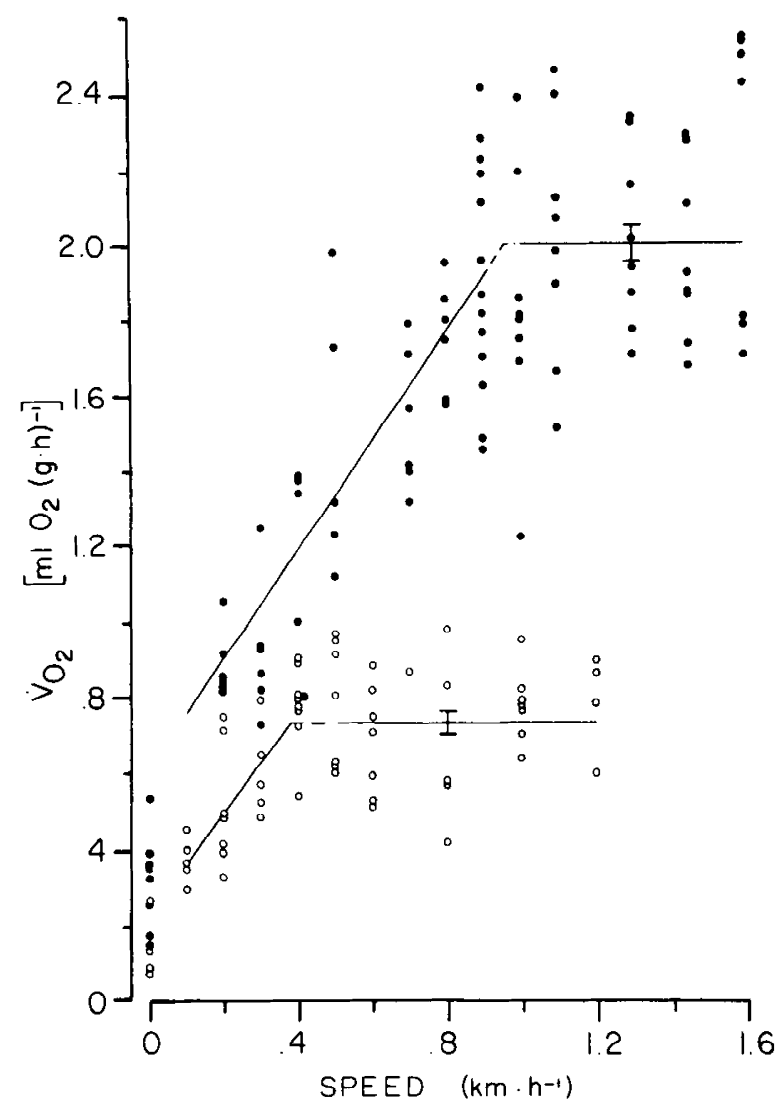

FIG. 3. Mass-specific $\mathrm{O}_{2}$ consumption $\left(\mathrm{V}_{2}\right)$ as a function of walking speed in $D$. dorsalis at $25^{\circ} \mathrm{C}$ (open circles) and $40^{\circ} \mathrm{C}$ (closed circles). Broken lines, extrapolations from data base. See text for method of calculating regression equations. 
Testing for parallelism (16) reveals that the slopes of these lines are statistically indistinguishable $(t=0.457, P$ $>0.25)$. The difference between $y$-intercepts is significant $(t=2.479, P<0.025)$ and is responsible for the difference between the two lines at any speed within the range of both.

The following linear equations best describe the relationships between $\dot{V}_{2}$ and speeds in the ranges through which time on the treadmill declines progressively

$$
\begin{array}{rlrl}
25^{\circ} \mathrm{C}: & \dot{\mathrm{Vo}}_{2} & =0.697+0.048(\mathrm{~S}) & 0.5 \leq \mathrm{S} \leq 1.2 \\
n & =31 ; r=0.08 ; 0.5<P<0.75 \\
40^{\circ} \mathrm{C}: & \dot{\mathrm{Vo}}_{2} & =1.500+0.392(\mathrm{~S}) \quad 1.0 \leq \mathrm{S} \leq 1.6 \\
n & =39 ; r=0.27 ; 0.05<P<0.10
\end{array}
$$

In neither case is the slope significantly different from zero, and testing for parallelism shows that the slopes are not significantly different from each other $(t=1.318,0.05$ $<P<0.10$ ). For each temperature, one-way analysis of variance reveals no significant differences among groups of $\mathrm{VO}_{2}$ values in the range of speeds to which either $E q$. 7 or $E q .8$ is applied. These $\mathrm{V}_{2}$ values have been pooled for calculation of a mean maximal $\dot{\mathrm{V}}_{2}\left(\mathrm{~V}_{\mathrm{V}_{2}}\right.$ max $)$ at each temperature. $\mathrm{V}_{2} o_{\max } \pm \mathrm{SEM}$ is plotted as a horizontal line with an error bar at its midpoint over the appropriate range of speeds for each temperature. At $25^{\circ} \mathrm{C}$, $\grave{\mathrm{V}} \mathrm{o}_{2 \text { max }}=0.736 \pm 0.028 \mathrm{ml} \mathrm{O} \cdot \mathrm{g}^{-1} \cdot \mathrm{h}^{-1}$, and at $40^{\circ} \mathrm{C}$, $\hat{\mathrm{V}}_{2}$ max $=2.002 \pm 0.046 \mathrm{ml} \mathrm{O} \cdot \mathrm{g}^{-1} \cdot \mathrm{h}^{-1}\left(\mathrm{Q}_{10}=1.96\right)$.

In Fig. 3, the lines representing Eqs. 5 and 6 and those representing $\hat{\mathrm{V}}_{\mathrm{O}_{2 \max }}$ for each temperature have been extrapolated (broken lines). The speeds at which these extrapolated lines intersect are termed the maximum aerobic speeds. For each temperature, these speeds serve as estimates of the exact speeds at which $\mathrm{VO}_{2}$ max are attained. These extrapolations are necessary because the

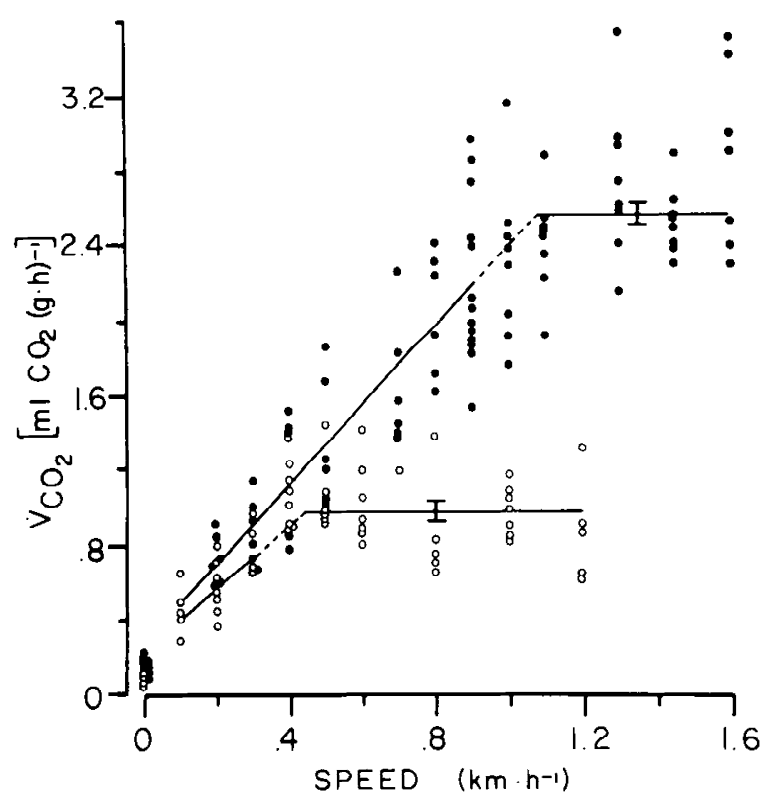

FIG. 4. Mass-specific $\mathrm{CO}_{2}$ production ( $\left(\mathrm{VCO}_{2}\right)$ as a function of walking speed in $D$. dorsalis at $25^{\circ} \mathrm{C}$ (open circles) and $40^{\circ} \mathrm{C}$ (closed circles). Broken lines, extrapolations from data base. See text for method of calculating regression equations. data set is discrete, not continuous. There is a very striking similarity between the highest speed sustained for $15 \mathrm{~min}$ by more than half the lizards (Fig. 1), and the speed at which $\tilde{\mathrm{V}}_{2 \max }$ is attained. At $25^{\circ} \mathrm{C}$, the highest sustainable speed is $0.3 \mathrm{~km} \cdot \mathrm{h}^{-1}$ and $\mathrm{V}_{2} \mathrm{O}_{\text {max }}$ is attained at $0.38 \mathrm{~km} \cdot \mathrm{h}^{-1}$. At $40^{\circ} \mathrm{C}$, the highest sustainable speed is $0.8 \mathrm{~km} \cdot \mathrm{h}^{-1}$ and $\hat{\mathrm{V}} \mathrm{O}_{2}$ max is attained at $0.96 \mathrm{~km} \cdot \mathrm{h}^{-1}$.

Mass-specific $\mathrm{CO}_{2}$ production $\left(\dot{\mathrm{V}} \mathrm{CO}_{2}\right)$ of animals on the treadmill is reported in Fig. 4. The difference between the average resting $\dot{\mathrm{V}}_{2}\left(\mathrm{~V}^{\dot{C}} \mathrm{CO}_{2 \text { rest }}\right)$ obtained at $25^{\circ} \mathrm{C}$ $\left(\hat{\mathrm{V}}_{\mathrm{O}_{2} \text { rest }}=0.089 \pm 0.023 \mathrm{ml} \mathrm{CO} \cdot \mathrm{g}^{-1} \cdot \mathrm{h}^{-1} ; n=4\right)$ and that obtained at $40^{\circ} \mathrm{C}\left(\hat{V}_{2} o_{2}\right.$ rest $=0.175 \pm 0.015 \mathrm{ml} \mathrm{CO}{ }_{2} \cdot \mathrm{g}^{-1}$. $\left.\mathrm{h}^{-1} ; n=8\right)$ is significant $\left(t=3.534, P<0.005 ; \mathrm{Q}_{10}=1.57\right)$. At each temperature, $\dot{\mathrm{V}} \mathrm{CO}_{2}$ increases linearly with speed up to an apparent maximum $\left(\dot{\mathrm{V}}_{2} \mathrm{O}_{2 \mathrm{xa}}\right)$, and that level is not exceeded at higher speeds. For each temperature, the data are described by the best-fitting pair of linear equations chosen by the criterion of minimizing the residual sums of squares as done previously for $\dot{\mathrm{V}}_{2}$. The following linear equations best describe the relationships between submaximal $\mathrm{V}_{\mathrm{CO}_{2}}$ and speed

$$
\begin{aligned}
25^{\circ} \mathrm{C}: \quad \dot{\mathrm{V}_{C O}} & =0.237+1.692(\mathrm{~S}) \quad 0.1 \leq \mathrm{S} \leq 0.3 \\
n & =16 ; r=0.69 ; P<0.005 \\
40^{\circ} \mathrm{C}: \quad \dot{\mathrm{V} O_{2}} & =0.297+2.102(\mathrm{~S}) \quad 0.2 \leq \mathrm{S} \leq 0.9 \\
n & =48 ; r=0.86 ; P<0.0005
\end{aligned}
$$

By using a dummy-variable multiple regression model and pooling all $\dot{\mathrm{CO}}_{2}$ values, the slopes and $y$-intercepts of Eqs. 9 and 10 can be compared simultaneously in a test for coincidence (16). The results of this method indicate that the two lines are coincident over the range of speeds shared by both $(F=0.511,0.25<P<0.50)$. The relationships between $\mathrm{VCO}_{2}$ and nonsustainable speed are best described by the following linear equations

$$
\begin{array}{rlrl}
25^{\circ} \mathrm{C}: & \dot{\mathrm{V} O_{2}} & =1.147-0.212(\mathrm{~S}) & 0.4 \leq \mathrm{S} \leq 1.2 \\
n & =39 ; r=0.28 ; 0.05<P<0.10 \\
40^{\circ} \mathrm{C}: & \dot{\mathrm{V} O_{2}} & =1.578+0.770(\mathrm{~S}) & 1.0 \leq \mathrm{S} \leq 1.6 \\
n & =39 ; r=0.42 ; P<0.005
\end{array}
$$

One-way analysis of variance reveals no significant differences among groups of $\dot{\mathrm{VCO}}_{2}$ values included in the ranges of speeds to which $E q .11$ and $E q .12$ are applied. Thus, values are pooled, the mean $\pm \mathrm{SE}$ of all $\dot{\mathrm{V}} \mathrm{CO}_{2}$ values for each temperature is plotted as a horizontal line through the appropriate speed range, and this value is termed the mean maximum $\dot{\mathrm{V}}_{\mathrm{CO}_{2}}\left(\dot{\mathrm{V}} \mathrm{CO}_{2} \max \right)$. At $25^{\circ} \mathrm{C}$, $\widehat{\mathrm{V}} \mathrm{CO}_{2 \max }=0.994+0.034 \mathrm{ml} \mathrm{CO}{ }_{2} \cdot \mathrm{g}^{-1} \cdot \mathrm{h}^{-1}$, and at $40^{\circ} \mathrm{C}$, $\hat{\mathrm{V}} \mathrm{CO}_{2 \max }=2.56 \mathrm{ml} \mathrm{CO} \cdot \mathrm{g}^{-1} \cdot \mathrm{h}^{-1}\left(\mathrm{Q}_{10}=1.89\right)$.

The ratio of $\mathrm{CO}_{2}$ production to $\mathrm{O}_{2}$ consumption (respiratory exchange ratio; $\mathrm{R}=\dot{\mathrm{V}} \mathrm{CO}_{2} \div \dot{\mathrm{V}} \mathrm{o}_{2}$ ) is presented as a function of speed in Fig. 5. The values of $\mathrm{VCO}_{2}$ and $\dot{\mathrm{VO}}_{2}$ used in calculating $\mathrm{R}$ were measured simultaneously. At each temperature, a single linear regression model is fit to the data over the entire range of speeds. Resting $R$ values were excluded from regression analysis. The following linear equations describe the relationships between $\mathbf{R}$ and speed 

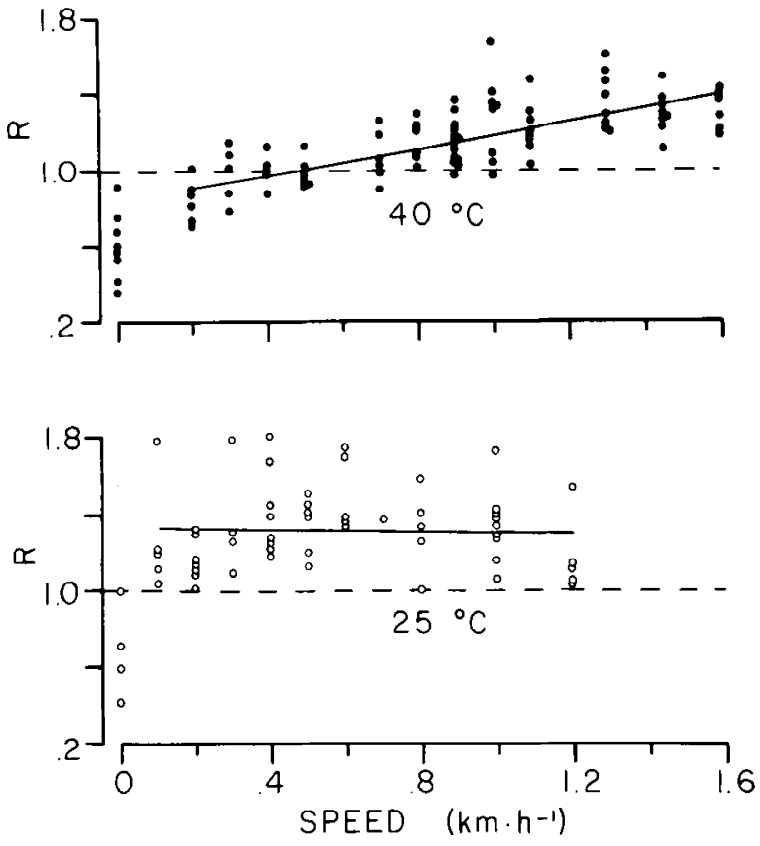

FIG. 5. Respiratory exchange ratio $\left(\mathrm{R}=\dot{\mathrm{V}} \mathrm{CO}_{2} \div \dot{\mathrm{V}} \mathrm{O}_{2}\right)$ as a function of walking speed in D. dorsalis at $25^{\circ} \mathrm{C}$ (open circles) and $40^{\circ} \mathrm{C}$ (closed circles). See text for method of calculating regression equations.

$$
\begin{aligned}
25^{\circ} \mathrm{C}: & \mathrm{R}=1.329-0.024(\mathrm{~S}) \\
& n=55 ; r=0.04 ; P>0.5 \\
40^{\circ} \mathrm{C}: & \mathrm{R}=0.845+0.339(\mathrm{~S}) \\
& n=87 ; r=0.73 ; P<0.0005
\end{aligned}
$$

The slope of Eq. 13 is not significantly different from zero, indicating no clear relationship between $\mathrm{R}$ and speed at $25^{\circ} \mathrm{C}$. However, at $40^{\circ} \mathrm{C}$, the slope is significant; $\mathrm{R}$ appears to increase over the entire range of speeds at which measurements were made.

\section{DISCUSSION}

Oxygen consumption and locomotory energetics. In $D$. dorsalis engaged in quadrupedal locomotion at 25 or $40^{\circ} \mathrm{C}$, the mass-specific rate of oxygen consumption $\left(\dot{\mathrm{VO}}_{2}\right)$ increases linearly with increasing speed up to a temperature-dependent maximum $\left(\dot{\mathrm{V}}_{2}\right.$ max $)$. The relationship between locomotory speed and $\mathrm{V}_{2}$ is the most commonly accepted basis for analyses of locomotory energetics (20). Conceptually, $\mathrm{VO}_{2}$ during anaerobic activity can be compartmentalized into maintenance costs, postural costs, and aerobic power input into the forward locomotory effort itself. Practically, it is difficult to isolate the energetic inputs of each of these factors. The aerobic maintenance and postural costs of an animal walking on a treadmill have been represented by the extrapolated $\dot{\mathrm{V}} \mathrm{O}_{2}$ at zero speed, the $y$-intercept (20). For studies investigating the cost of locomotion per se, these costs are eliminated by subtracting the $y$-intercept from the aerobic metabolic expenditure during activity and dividing the difference by locomotory speed to obtain the net cost of locomotion (20). This value is given by the slope of $\dot{\mathrm{VO}}_{2}$ as a function of speed. The net cost of locomotion of Dipsosaurus walking on a treadmill is $1.323 \mathrm{ml} \mathrm{O} \cdot \mathrm{g}^{-1}$. $\mathrm{km}^{-1}$ at $25^{\circ} \mathrm{C}(E q .5)$ and $1.442 \mathrm{ml} \mathrm{O} \cdot \mathrm{g}^{-1} \cdot \mathrm{km}^{-1}$ at $40^{\circ} \mathrm{C}$ (Eq. 6). A predicted value of $1.409 \mathrm{ml} \mathrm{O} \cdot \mathrm{g}^{-1} \cdot \mathrm{km}^{-1}$ is obtained by inserting the mean body mass $(m=51.3 \mathrm{~g})$ of animals used in the present study into the following allometric equation derived for lizards (14)

$$
\text { net cost of locomotion }=3.77 \mathrm{~m}^{-0.25}
$$

The experimental values determined at 25 and $40^{\circ} \mathrm{C}$ both fall within the $95 \%$ confidence interval of the predicted value.

The values of net cost of locomotion in Dipsosaurus at 25 or $40^{\circ} \mathrm{C}$ are not significantly different from each other, thereby indicating temperature independence between the experimental $\mathrm{T}_{\mathrm{b}}$ 's. This pattern has been reported for Uromastix aegyptius (12), and a similar pattern can be obtained from data collected on Iguana iguana $(17,18)$.

An estimate of the energetic cost of locomotion per se is given in different terms by subtracting $\dot{\mathrm{V}}_{2}$ rest, measured for an animal resting on the treadmill prior to walking, from $\mathrm{V}_{\mathrm{O}_{2}}$ measured during walking. This yields the increment in $\dot{\mathrm{V}}_{2}$ above $\dot{\mathrm{Vo}}_{2}$ rest for an animal walking at some sustainable speed. The net energetic cost of walking $\left(\mathrm{ml} \mathrm{O}_{2} \cdot \mathrm{g}^{-1} \cdot \mathrm{h}^{-1}\right)$ calculated by this method for Iguana is reported to be temperature independent (18). This implies either that the $y$-intercept equals $\dot{V} o_{2}$ rest in Iguana, contrary to what has been reported for Gerrhonotus, Tupinambis, Ctenosaura, Varanus (1), and Amblyrhynchus (14), or, alternatively, that the increment in $\dot{\mathrm{VO}}_{2}$ above $\dot{\mathrm{VO}}_{2}$ rest is temperature independent. A similar calculation is not possible for the data on Uromastix, but it is a reasonable assumption that the incremental change in $\mathrm{VO}_{2}$ at any sustainable speed declines with increasing temperature, because the total aerobic power input is reported as being temperature independent (12). Neither of these patterns occurs in Dipsosaurus. Instead, the net energetic cost of walking at any sustainable speed increases with increasing temperature. The total power input of walking seems to involve something more than a straightforward addition to $\mathrm{V}_{2}$ rest attributable to the power output of locomotion per se. Since the slope of $\dot{\mathrm{VO}}_{2}$ vs. speed is temperature independent, it follows that the difference between the $y$-intercept and $\dot{\mathrm{Vo}}_{2 \text { max }}$ increases with increasing temperature to account for the incremental change in $\hat{V O}_{2}$ at any speed as $\mathrm{T}_{\mathrm{b}}$ increases. Thus, the energetic cost of postural adjustments and other physiological changes requisite to locomotion shows a positive thermal dependence between 25 and $40^{\circ} \mathrm{C}$ in Dipsosaurus.

The total cost of locomotion (20), alternately termed the cost of transport (22), is calculated as the massspecific aerobic power input divided by the speed of locomotion at or below the maximum aerobic speed. This is the total energetic cost accrued by a walking animal and is the quantity most useful for extrapolating laboratory energetic data to the ecological energetics of an animal (6). The total cost of locomotion (Ctot) declines with increasing speed according to a hyperbolic function as shown in Fig. 6. Since the time spent traversing a unit distance decreases as speed increases, the duration of maintenance and postural costs decreases and the contribution of these costs to Ctot decreases. Therefore, the 


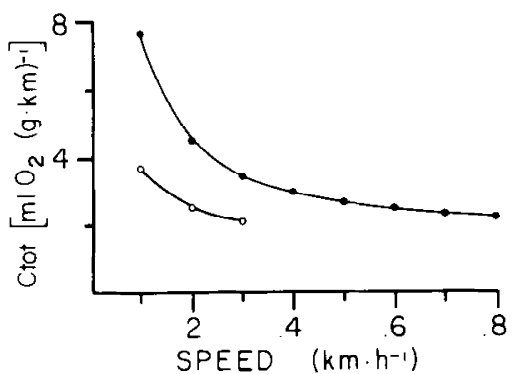

FIG. 6. Total cost of locomotion (Ctot) as a function of walking speed in $D$. dorsalis at $25^{\circ} \mathrm{C}$ (open circles) and $40^{\circ} \mathrm{C}$ (closed circles). Minimum cost of transport is attained at highest sustainable speed. See text for method of generating curves.

minimum cost of transport (22) is attained at the highest sustainable speed. In Dipsosaurus, Ctot at any speed sustainable at both 25 and $40^{\circ} \mathrm{C}$ is higher at $40^{\circ} \mathrm{C}$. For example, the total cost of locomotion at $0.2 \mathrm{~km} \cdot \mathrm{h}^{-1}$ is $4.54 \mathrm{ml} \mathrm{O}{ }_{2} \cdot \mathrm{g}^{-1} \cdot \mathrm{km}^{-1}$ at $40^{\circ} \mathrm{C}$ and $2.52 \mathrm{ml} \mathrm{O} \cdot \mathrm{g}^{-1} \cdot \mathrm{km}^{-1}$ at $25^{\circ} \mathrm{C}$. However, Dipsosaurus at $40^{\circ} \mathrm{C}$ are able to sustain $0.8 \mathrm{~km} \cdot \mathrm{h}^{-1}$ whereas those at $25^{\circ} \mathrm{C}$ can sustain only 0.3 $\mathrm{km} \cdot \mathrm{h}^{-1}$, and the minimum cost of transport, attained at the maximum sustainable speed, is unchanged. At $25^{\circ} \mathrm{C}$, the minimum cost of transport (calculated from $E q .5$ ), attained at $0.3 \mathrm{~km} \cdot \mathrm{h}^{-1}$, is $2.12 \mathrm{ml} \mathrm{O} \cdot \mathrm{g}^{-1} \cdot \mathrm{km}^{-1}$; at $40^{\circ} \mathrm{C}$, it is $2.22 \mathrm{ml} \mathrm{O} \cdot \mathrm{g}^{-1} \cdot \mathrm{km}^{-1}$ (calculated from $E q$. 6) at 0.8 $\mathrm{km} \cdot \mathrm{h}^{-1}$, values that are strikingly similar. The cost of walking a given distance at a high percentage of the maximum sustainable speed, as might be expected for a foraging animal crossing an exposed area, becomes no more energetically expensive as $\mathrm{T}_{\mathrm{b}}$ increases. By thermoregulating at $40^{\circ} \mathrm{C}$, Dipsosaurus greatly broadens its range of aerobic speeds and may avoid an obligatory increase in the total cost of locomotion by walking at faster speeds.

Respiratory exchange ratio and anaerobic contribu. tion. At both 25 and $40^{\circ} \mathrm{C}$, the rate of $\mathrm{CO}_{2}$ production $\left(\mathrm{V}_{\mathrm{CO}_{2}}\right)$ increases with increasing speed up to apparent maximal levels. The respiratory exchange ratio $(\mathrm{R}=$ $\dot{\mathrm{V}} \mathrm{CO}_{2} / \dot{\mathrm{VO}}_{2}$ ) shows no clear relationship with speed at $25^{\circ} \mathrm{C}$, while it appears to increase steadily with increasing speed at $40^{\circ} \mathrm{C}$. These data must be interpreted cautiously: an increase in $\mathrm{V}_{\mathrm{CO}_{2}}$ may reflect increased metabolic production of $\mathrm{CO}_{2}$, increased respiratory excretion of $\mathrm{CO}_{2}$ as a consequence of hyperventilation in response to metabolic demand for $\mathrm{O}_{2}$ (respiratory overcompensation), or increased respiratory excretion of $\mathrm{CO}_{2}$ as a means of buffering anaerobically formed lactic acid. Respiratory exchange ratios not exceeding one are indicative of aerobically supported activity, but $R$ values in excess of one do not necessarily indicate anaerobiosis.

No values of $\mathrm{R}$ under one were measured for Dipsosaurus walking at $25^{\circ} \mathrm{C}$. It is likely that the initial phase of walking is supported by anaerobic metabolism. Both Cnemidophorus (9) and Amblyrhynchus (15) have R values in excess of one during the first few minutes of walking at sustainable speeds at PBT. After this period, $R$ decreases to one or lower, indicative of aerobic metabolism. The change in $\mathrm{R}$ is paralleled by a rise and subsequent decline in blood lactate in Amblyrhynchus (15). Similar data are unavailable for small lizards, because it has not been possible to make simultaneous measurements of metabolic gases and blood lactate during activity. A similar transient dependence on anaerobic metabolism may be occurring in Dipsosaurus, however, and this may be more prolonged at 25 than at $40^{\circ} \mathrm{C}$. The lag between the onset of activity and the increase in $\mathrm{O}_{2}$ consumption is accentuated by low $\mathrm{T}_{\mathrm{b}}$ in Sceloporus occidentalis, a closely related species (8). In Anolis carolinensis, another iguanid lizard, the rate of removal of lactate is depressed by low $T_{b}(10)$. Gleeson (15) has shown that there is a delay in the diffusion of lactate into the blood of Amblyrhynchus at low $\mathrm{T}_{\mathrm{b}}$. If Dipsosaurus encounters similar delays in oxygen delivery and lactate removal at low $T_{b}, 15$ min may be insufficient for respiratory buffering of the accumulated lactic acid at $25^{\circ} \mathrm{C}$, and $R$ would remain above one during the entire period of activity.

At both 25 and $40^{\circ} \mathrm{C}$, the final $\mathrm{R}$ values, occurring at nonsustainable speeds of 1.2 and $1.6 \mathrm{~km} \cdot \mathrm{h}^{-1}$, respectively, are well above one. These values reflect anaerobic support of nonsustainable activity. Even at $40^{\circ} \mathrm{C}$, Dipsosaurus are unable to sustain high locomotory speeds when compared to those sustained by similarly sized mammals. However, like other lizards [see Bennett (4)], these are able to broaden their range of locomotory speeds by recruiting additional anaerobic support for brief bouts of activity. As the intensity of activity heightens, i.e., as locomotory speed increases, the duration of these bouts declines toward some minimal level, as shown in Fig. 1. In the present experiments, bouts of running were discontinued when they became too short for collection of meaningful metabolic gas records. Burst speeds from standing start, measured on Dipsosaurus in the laboratory, averaged 4.7 and $7.8 \mathrm{~km} \cdot \mathrm{h}^{-1}$ at 25 and $40^{\circ} \mathrm{C}$, respectively (5). These observations, together with those presented in Fig. 1, indicate that the capacity for Dipsosaurus to engage in bouts of nonsustainable activity increases with increasing $\mathrm{T}_{\mathrm{b}}$. Belkin (2) reported field running speeds of Dipsosaurus $\left(\mathrm{T}_{\mathrm{b}}: 39-44^{\circ} \mathrm{C}\right)$ to average $26.3 \mathrm{~km} \cdot \mathrm{h}^{-1}$ with a maximum of $30.6 \mathrm{~km} \cdot \mathrm{h}^{-1}$. The duration of these bursts of activity was measured in seconds. Clearly, this represents an advantage associated with foraging at high $\mathrm{T}_{\mathrm{b}}$ in that it enhances the lizard's ability to flee from predators.

Aerobic limits and endurance. The data analysis presented in Table 1 for measurements of endurance and

TABLE 1. Thermal dependence of activity capacity and aerobic metabolism in $D$. dorsalis at 25 and $40^{\circ} \mathrm{C}$

\begin{tabular}{|c|c|c|c|}
\hline \multirow{2}{*}{ Measurement } & \multicolumn{2}{|c|}{$\mathrm{T}_{\mathrm{b}},{ }^{\circ} \mathrm{C}$} & \multirow{2}{*}{$\mathbf{Q}_{10}$} \\
\hline & 25 & 40 & \\
\hline Max sustainable speed, $\mathrm{km} \cdot \mathrm{h}^{-1}$ & 0.3 & 0.8 & 1.93 \\
\hline $\mathrm{SMR},{ }^{*} \mathrm{ml} \mathrm{O}_{2} \cdot \mathrm{g}^{-1} \cdot \mathrm{h}^{-1}$ & 0.05 & 0.13 & 1.90 \\
\hline$\dot{\mathrm{V}} \mathrm{O}_{2 \max }, \mathrm{ml} \mathrm{O} 2 \cdot \mathrm{g}^{-1} \cdot \mathrm{h}^{-1}$ & 0.736 & 2.002 & 1.96 \\
\hline$y$-Intercept, $\mathrm{ml} \mathrm{O}_{2} \cdot \mathrm{g}^{-1} \cdot \mathrm{h}^{-1}$ & 0.240 & 0.620 & 1.89 \\
\hline$y$-Intercept $\div$ SMR & 4.80 & 4.77 & 1.00 \\
\hline$\dot{\mathrm{V}} \mathrm{O}_{2 \max } \div \mathrm{SMR}$ (factorial aerobic scope) & 14.80 & 15.38 & 1.03 \\
\hline
\end{tabular}

$T_{b}$, body temperature; $Q_{10}$, thermal dependence; SMR, standard metabolic rate. ${ }^{*}$ Data from Bennett and Dawson (7). 
aerobic activity metabolism reveals a very close relationship between sustainable levels of activity and maximum rates of $\mathrm{O}_{2}$ consumption. Between 25 and $40^{\circ} \mathrm{C}$, the thermal dependencies of maximum sustainable speed (Fig. 1) and $\dot{V} \mathrm{O}_{2 \max }$ (Fig. 3) are nearly identical, each having a $\mathrm{Q}_{10}$ approximately equal to 1.9 . Moreover, there is a close similarity between the maximum sustainable speeds, reported in Fig. 1, and the maximum aerobic speeds, reported in Fig. 3. The discrepancies between these two speeds probably represent nothing more than a limitation of the data collection (i.e., discrete instead of continuous) and analysis. The similarities between maximum sustainable speeds and maximum aerobic speeds are suggestive of a common physiological system limiting both $\mathrm{Vo}_{2}$ and aerobic activity. Alternately, one of these functions may limit the other; for example, $\mathrm{O}_{2}$ delivery may limit $\dot{\mathrm{V}} \mathrm{O}_{2}$ max and this, in turn would limit aerobic activity. In the Reptilia, there is a broad correlation between maximal rates of $\mathrm{O}_{2}$ delivery and behavioral levels of activity [see Bennett (4)], more active species generally having higher $\dot{\mathrm{V}}_{2 \text { max }}$. The data presented here suggest that $\dot{V}_{o_{2} \text { max }}$ plays a permissive role in defining the maximal level of sustainable activity. Thus, one behavioral benefit of having a high $\mathrm{VO}_{2}$ max is a broadening of the range of sustainable speeds available to an animal. These advantages undoubtedly have served as selective pressures for high $\mathrm{T}_{\mathrm{b}}$.

It is intriguing that the near identity among $Q_{10}$ extends to standard metabolic rate (SMR) (7) and the $y$-intercept (Fig. 3), both having $\mathrm{Q}_{10}$ approximately equal to 1.9 . From this, several interesting relationships follow. The ratio of $y$-intercept to SMR equals 4.8 at both 25 and $40^{\circ} \mathrm{C}$, showing no thermal dependence $\left(Q_{10}=1\right)$. Likewise, the ratio of $\widehat{V}_{O_{2} \text { max }}$ to SMR (the factorial index of aerobic expansibility) shows no thermal dependence, being approximately 15 at both experimental temperatures. Extending this, if speed is expressed as percent of maximum sustainable speed at either temperature, then the ratio of $\dot{\mathrm{VO}}_{2}$ at that speed to SMR shows no thermal dependence, although the absolute speed increases with temperature. From this analysis, it becomes clear that $\dot{\mathrm{VO}}_{2}$ max and, consequently, maximum sustainable speed can be predicted for Dipsosaurus at any $\mathrm{T}_{\mathrm{b}}$ between 25 and $40^{\circ} \mathrm{C}$ based on the net cost of locomotion (the slope of $\dot{\mathrm{VO}}_{2}$ vs. speed) and SMR.

Bennett and Dawson (7) reported factorial aerobic increments in Dipsosaurus of 10 at $25^{\circ} \mathrm{C}$ and 17 at $40^{\circ} \mathrm{C}$. A value of about 15 is obtained for both temperatures from the data in the present report. It is likely that the difference between the two reports is due to different methods of determining maximal rates of $\mathrm{O}_{2}$ consumption. The values of Bennett and Dawson (7) are more correctly termed integrated rates of $\mathrm{O}_{2}$ consumption during the initial $2 \mathrm{~min}$ of forced maximal activity. The values are likely to underestimate $\dot{\mathrm{V}}_{2}$ max at low $\mathrm{T}_{\mathrm{b}}$, since the speed of develoment of maximal rates of $\mathrm{O}_{2}$ consumption is retarded by low $T_{b}(8)$.

In summary, the data collected and presented in this study are particularly meaningful in the context of the locomotory biology of Dipsosaurus. In terms of aerobic metabolism and activity, there are advantages and disadvantages associated with locomotion at either of the experimental body temperatures. Operation at $25^{\circ} \mathrm{C}$ is advantageous, since SMR is lower and walking at any speed requires less energetic input than at $40^{\circ} \mathrm{C}$. Thus, locomotion at low $\mathrm{T}_{\mathrm{b}}$ conserves energy. The obvious disadvantage is that aerobic limits on activity are attained at low speeds, endurance is low, and anaerobic metabolism must be recruited at low levels of exertion. By thermoregulating at $40^{\circ} \mathrm{C}$, Dipsosaurus greatly increases its range of sustainable speeds and behaviors. The energetic disadvantages of high-temperature function are that SMR is higher and walking at any speed is more costly than at $25^{\circ} \mathrm{C}$. However, the minimum energetic cost of traveling a unit distance, the minimum cost of transport (Fig. 6), which depends not only on the metabolic rate but also on the locomotory speed, is temperature independent. Thus, by walking at or near its maximum aerobic speed, Dipsosaurus is able to avoid an obligatory increase in the energetic cost of walking associated with maintenance of a relatively high body temperature.

We thank Drs. Todd T. Gleeson and Robert W. Putnam for critically reading the manuscript.

This study was supported by National Science Foundation Grant PCM-77-24208 and National Institutes of Health Grant K04-AM-00351.

Received 21 November 1980; accepted in final form 11 May 1981.

\section{REFERENCFS}

1. BAKKER, R. T. Locomotor energetics of lizards and mammals compared (Abstract). Physiologist 15: 76, 1972.

2. Belkin, D. A. The running speeds of the lizards Dipsosaurus dorsalis and Callisaurus draconoides. Copeia 1961(2): 223-224, 1961.

3. Bennetr, A. F. The effect of activity on oxygen consumption, oxygen debt, and heart rate in the lizards Varanus gouldii and Sauromalus hispidus. J. Comp. Physiol. 79: 259-280, 1972.

4. Bennett, A. F. Activity metabolism of the lower vertebrates. Annu. Rev. Physiol. 40: 447-469, 1978.

5. BenNetT, A. F. The thermal dependence of lizard behavior. Anim. Behav. 28: 752-762, 1980.

6. BENNETT, A. F. The energetics of reptilian activity. In: Biology of the Reptilia, edited by C. Gans and W. R. Dawson. New York: Academic, 1981. In press.

7. Bennett, A. F., ANd W. R. Dawson. Aerobic and anaerobic metabolism during activity in the lizard Dipsosaurus dorsalis. J. Comp. Physiol. 81: 289-299, 1972.

8. Bennett, A. F., And T. T. Gleeson. Activity metabolism in the lizard Scleoporus occidentalis. Physiol. Zool. 49: 65-76, 1976.

9. Bennett, A. F., AND T. T. Gleeson. Metabolic expenditure and the cost of foraging in the lizard Cnemidophorus murinus. Copeia 1979(4): 573-577, 1979.

10. Bennett, A. F., AND P. Licht. Anaerobic metabolism during activity in lizards. J. Comp. Physiol. 81: 277-288, 1972.

11. DewitT, C. B. Precision of thermoregulation and its relation to environmental factors in the desert iguana, Dipsosaurus dorsalis. Physiol. Zool. 40: 49-66, 1967.

12. DMI'EL, R., AND D. RAPPEPort. Effect of temperature on metabolism during running in the lizard Uromastix aegyptius. Physiol. Zool. 49: 77-84, 1976.

13. FRY, F. E. J. Effects of the environment on animal activity. Publ. Ont. Fish. Res. Lab. 68, 1947.

14. Gleeson, T. T. Foraging and transport costs in the Galapagos marine iguana, Amblyrhynchus cristatus. Physiol. Zool. 52: 549$557,1979$. 
15. Gleeson, T. T. Metabolic recovery from exhaustive activity by a large lizard. J. Appl. Physiol.: Respirat. Environ. Exercise Physiol. 48: 689-694, 1980.

16. Kleinbaum, D. G., AND L. L. KupPer. Applied Regression Analysis and Other Multivariate Methods. North Scituate, MA: Duxbury, 1978.

17. Moberly, W. R. The metabolic responses of the common iguana, Iguana iguana, to activity under restraint. Comp. Biochem. Physiol. 27: 1-20, 1968.

18. Moberly, W. R. The metabolic responses of the common iguana, Iguana iguana, to walking and diving. Comp. Biochem. Physiol. 27: 21-32, 1968 .

19. Norris, K. S. The ecology of the desert iguana, Dipsosaurus dorsalis. Ecology 34: 265-287, 1953.
20. Schmidt-Nielsen, K. Locomotion: energy cost of swimming, flying, and running. Science 177: 222-228, 1972.

21. Taylor, C. R., K. Schmidt-Nielsen, and J. L. RaAB. Scaling of energetic cost of running to body size in mammals. Am. J. Physiol. 219: 1104-1107, 1970.

22. TuCKer, V. A. Energetic cost of locomotion in animals. Comp. Biochem. Physiol. 34: 841-846, 1970.

23. Wilson, K. J. The relationship of oxygen supply for activity to body temperature in four species of lizards. Copeia 1974: 920-934, 1974.

24. Withers, P. C. Measurement of $\dot{\mathrm{VO}}_{2}, \dot{\mathrm{V}}_{\mathrm{CO}}$, and evaporative water loss with a flow-through mask. J. Appl. Physiol.: Respirat. Environ. Exercise Physiol. 42: 120-123, 1977.

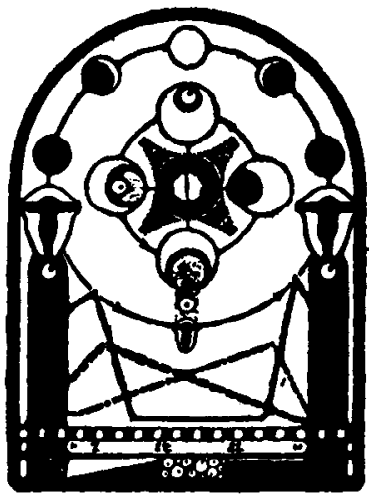

